The FASEB Journal express article 10.1096/fj.02-0459fje. Published online January 2, 2003.

\title{
Cyclic strain inhibits switching of smooth muscle cells to an osteoblast-like phenotype
}

\author{
Janeta Nikolovski, ${ }^{*}$ Byung-Soo Kim, ${ }^{\S}$ and David J. Mooney*,†, \\ *Department of Biomedical Engineering, ${ }^{\dagger}$ Department of Chemical Engineering, and \\ ${ }^{\$}$ Department of Biologic and Materials Sciences, University of Michigan, Ann Arbor, MI; \\ ${ }^{\S}$ Department of Chemical Engineering, Hanyang University, Haengdang-dong, Seongdong-gu, \\ Seoul, Korea \\ Corresponding author: David J. Mooney, Department of Chemical Engineering, University of \\ Michigan, 2300 Hayward Avenue, 3074 H. H. Dow, Ann Arbor, MI 48109-2136. E-mail: \\ mooneyd@umich.edu
}

\section{ABSTRACT}

Ectopic calcification is commonly associated with cardiovascular disease, injury, aging, and biomaterial implantation. We hypothesized that the normal mechanical environment of smooth muscle cells (SMCs) inhibits a phenotypic switch to a pattern of gene expression more typical for bone and inducive for calcification. This hypothesis was tested using a 3-D engineered smooth muscle tissue model subjected to cyclic mechanical strain. This simplified model maintained a 3-D tissue architecture while eliminating systemic effects as can be seen with in vivo models. All engineered tissues were found to express bone-associated genes (osteopontin, matrix gla protein, alkaline phosphatase, and the transcription factor CBFA-1). Strikingly, however, expression of these genes was down-regulated in tissues exposed to cyclic strain at all time points ranging from 5 to 150 days. Furthermore, long-term strain played a protective role in regard to calcification, as unstrained tissues exhibited increased calcium deposition with respect to strained tissues. The results of this study suggest that without an appropriate mechanical environment, SMCs in 3-D culture undergo a phenotypic conversion to an osteoblast-like pattern of gene expression. This finding has significant implications for the mechanisms underlying a variety of cardiovascular diseases and indicates the broad utility of engineered tissue models in basic biology studies.

Key words: tissue engineering $\bullet$ mechanical strain $\bullet$ calcification $\bullet$ osteopontin $\bullet$ matrix gla protein

$\checkmark$ ctopic calcification, or calcium deposition in soft tissues, is a common problem associated with cardiovascular disease, many therapies used to treat cardiovascular disease (e.g., balloon angioplasty), and implantation of biomaterials $(1,2)$. Clinically, adverse effects of cardiovascular calcification include generally increased rigidity of tissues, rupture and dissection of tissues, and an increased risk of myocardial infarction (3).

Several studies have implicated smooth muscle cells (SMCs) as one of the primary cell types associated with arterial calcification. These cells have the ability to calcify in culture (4-6), and a calcifying cell subpopulation derived from the aortic media has also been identified that exhibits 
osteoblastic characteristics (7). Recently, it has been shown that the process of arterial calcification is an active, cell-controlled event, much like the process of calcification in bone (1, 3 ). The mechanisms regulating this process in smooth muscle remain unclear, but this process has been extensively studied in bone formation. Osteoblast differentiation occurs in several stages, involving the expression of various genes in each stage leading to mineralization (8). Proteins typically associated with bone formation appear to act as key mediators of calcification in the cardiovasculature as well. Molecular mediators of calcification in bone, including osteopontin (OPN) and its transcription factor core binding factor-1 (CBFA-1), matrix gla protein (MGP), and alkaline phosphatase, have been shown to be expressed by SMCs and associate with sites of calcification in vivo $(9,10)$ and in vitro $(7,11-14)$. Interestingly, OPN expression by SMCs is elevated during neointima formation following aortic injury $(9,15)$, and aortic rings excised from rats and grown statically in culture showed increased amounts of OPN and MGP with time (11).

It is likely that mechanical stimuli may mediate cardiovascular calcification. Mechanical strain is a strong regulator of SMC phenotype and is crucial for maintenance of SMCs in a differentiated state (16). SMCs in the cardiovascular system are constantly exposed to cyclic mechanical stretch and normally exist in a contractile, or differentiated, state. An altered mechanical environment causes these cells to revert to a synthetic phenotype, in which the cells lose their ability to contract and increase their proliferation, migration, and secretion of proteins (17). The altered mechanical environment resulting from atherosclerosis, vascular injury, and biomaterial implantation has been linked to SMC hypertrophy, hyperplasia, and migration. Strikingly, in bone and cultured bone cells, numerous studies have found that expression of genes associated with mineralization (e.g., OPN) and calcification itself is sensitive to the mechanical environment (18-20).

We hypothesize that the lack of an appropriate mechanical environment induces a phenotypic switch of cultured SMCs to a pattern of gene expression more typical for bone, leading to enhanced calcification. To address this hypothesis, a smooth muscle engineered tissue model was used in order to more closely mimic the natural 3-D architecture of smooth muscle in vivo than the typical 2-D systems used in in vitro studies. In this model, rat aortic SMCs were grown within type I collagen sponges. Rat SMCs were chosen to allow direct comparison with previous studies of the effect of cyclic strain on the maintenance of SMC phenotype in this system (21). This simplified system maintained a 3-D tissue architecture, while eliminating the complication of systemic effects that have been also shown to regulate biomineralization, such as macrophage infiltration and circulating factors (22).

\section{MATERIALS AND METHODS}

\section{Isolation and culture of rat aortic SMCs}

SMCs were isolated from rat aortas by using an adaptation of a previously published technique (21). In brief, the descending aortas of 100- to 150-g adult male Lewis rats (Charles River Laboratories, Wilmington, MA), after the removal of endothelium, adventitia, fat, and connective tissue, were cut into multiple small pieces and incubated under agitation with an orbital shaker $(60 \mathrm{rpm})$ for $90 \mathrm{~min}$ at $37^{\circ} \mathrm{C}$ in a sterile conical containing an enzymatic dissociation buffer. This buffer contained $0.125 \mathrm{mg} / \mathrm{ml}$ elastase (Sigma, St. Louis, MO), 1.0 
$\mathrm{mg} / \mathrm{ml}$ collagenase (CLS type I, $204 \mathrm{U} / \mathrm{mg}$, Worthington Biochemical, Freehold, NJ), 0.250 $\mathrm{mg} / \mathrm{ml}$ soybean trypsin inhibitor (type $1-\mathrm{S}$, Sigma), and $2.0 \mathrm{mg} / \mathrm{ml}$ crystallized bovine serum albumin (BSA; Gibco/Life Technologies, Gaithersburg, MD). Following the complete dissolution of the matrix, the resultant cell suspension was filtered through a $100-\mu \mathrm{m}$ Nitex filter (Tetko, Briarcliff Manor, NY) and centrifuged at $200 \mathrm{~g}$ for $5 \mathrm{~min}$. The pellet was resuspended in growth medium consisting of Medium 199 (Gibco) supplemented with $20 \%$ fetal bovine serum (FBS; Gibco), $2 \mathrm{mM}$ L-glutamine (Gibco), $100 \mathrm{U} / \mathrm{ml}$ penicillin (Gibco), and $0.1 \mathrm{mg} / \mathrm{ml}$ streptomycin (Gibco). Cells pooled from two to three aortas were seeded onto a tissue culture flask $\left(25 \mathrm{~cm}^{2}\right)$. SMCs were maintained in growth media containing $20 \%$ FBS until the first passage, whereas all subsequent cultures were grown in the presence of $10 \%$ FBS. SMCs between passage 6 and 15 were used in all experiments in this study.

\section{Cell seeding and application of mechanical strain}

For static, 2-D experiments, SMCs were seeded onto T25 flasks $\left(1 \times 10^{4}\right.$ cells $\left./ \mathrm{cm}^{2}\right)$ and grown for various times. Smooth muscle tissues were constructed by seeding cells onto $4 \times 1 \mathrm{~cm}, 3.5-\mathrm{mm}-$ thick, type I collagen sponges (Integra Life Science, Plainsboro, NJ) at a density of $2.1 \times 10^{6}$ cells $/ \mathrm{cm}^{3}$. After seeding, all samples were cultured for 3 days in petri dishes and then placed in spinner flasks (working volume $=50 \mathrm{ml}$, Bellco Glass; $40 \mathrm{rpm}$ ) and cultured for 7 additional days, with the medium changed every other day. Before strain application, the medium was changed and supplemented with $50 \mu \mathrm{g} / \mathrm{ml}$ ascorbic acid.

A custom-made mechanical strain device was used in these studies (Fig. 1). (21). With this device, sponges are held submersed in culture medium between two clamps. One clamp is moved back and forth by a crank attached to an eccentric disk, thereby applying strain to the substrate as the disk rotates. The entire device is maintained within an incubator during the course of experiments. The ability of this custom-made device to confer a uniform strain along the length of the substrate was assessed using a collagen sponge positioned within the device. Digital photographs (Sony, New York, NY) were taken initially and following the application of nominal strain of 7\% of initial length. Images were analyzed in Adobe Photoshop (Adobe, San Jose, CA), and strain was calculated by measuring the relaxed (initial) and distended (final) lengths at distinct positions within a grid pattern (parallel and perpendicular to strain direction) superimposed on the sponge.

Tissues receiving strain application were subjected to cyclic strain at a frequency of $1 \mathrm{~Hz}$ and an amplitude of 7\%. Designated control tissues were fixed at only one end within this device and moved at the same frequency and amplitude in a second bioreactor. At the end of each experiment, tissues were rinsed in phosphate-buffered saline (PBS) and either snap frozen in liquid $\mathrm{N}_{2}$ and stored frozen (for RNA analysis), immersed in lysis buffer (see formulation below) (23) and stored frozen (for protein analysis), or fixed (for histological analysis).

For strain application in 2-D studies, SMCs were seeded onto commercially available, flexible membranes (Bioflex; Flexcell Corp., McKeesport, PA) at $1 \times 10^{4}$ cells $/ \mathrm{cm}^{2}$ and were subjected to cyclic strain using a Flexercell unit (Flexcell Corp.). Cell seeding was confined to an area of 5 $\mathrm{cm}^{2}$ in the center of each well by using a Teflon ring weighted down by a washer in order to provide a uniform strain field to all cells. Bioflex plates were first exposed overnight to UV radiation from the sterilization bulb in a standard cell culture hood in order to activate the surface 
(24). Membranes were then precoated before seeding with type I collagen (Collaborative Biomedical Products, Bedford, MA) at a density of $2 \mu \mathrm{g} / \mathrm{cm}^{2}$ and then washed with PBS. Cells were allowed to adhere and spread for $24 \mathrm{~h}$ postseeding. Cells were subjected to cyclic strain at a frequency of $0.25 \mathrm{~Hz}$ ( $2 \mathrm{~s}$ strain, $2 \mathrm{~s}$ relaxation) and an amplitude of $7 \%$ for 2 days. At the end of each experiment, total RNA was isolated from cells by using Trizol and analyzed as described below.

\section{Northern blot analysis}

Total RNA from cells was isolated with Trizol (Life Technologies, Grand Island, NY) as per the manufacturer's instructions. RNA was quantified by fluorimetry, using Sybr Green-2 dye (Molecular Probes, Eugene, OR), and 5-10 $\mu \mathrm{g}$ were separated in a $1.25 \%$ agarose, $2.2 \mathrm{M}$ formaldehyde gel and transferred overnight to Hybond-N blotting membranes (Amersham, Arlington Heights., IL). The RNA was crosslinked to the membrane by exposure to a UV light source at 70,000 Joules $/ \mathrm{cm}^{2}$ (UV Stratalinker 2400, Stratagene, La Jolla, CA). OPN (a generous gift from M. Somerman [25]), MGP, and CBFA-1 (both generous gifts from R. Franceschi [26]), and the housekeeping gene glyceraldehyde phosphate dehydrogenase (GAPDH) cDNA probes were randomly labeled with a ${ }^{32} \mathrm{P}$ dCTP (Amersham). Membranes were sequentially hybridized using Rapid-hyb buffer (Amersham) at $65^{\circ} \mathrm{C}$ overnight. Membranes were washed progressively to high stringency $\left(0.2 \times \mathrm{SSC}, 0.1 \% \mathrm{SDS}\right.$ at $\left.65^{\circ} \mathrm{C}\right)$ and autoradiographed (BioMax MS film, Kodak) at $-70^{\circ} \mathrm{C}$ with an MS intensifying screen. Bands were quantified densitometrically by scanning films into Scion Image (NIH Image), and mRNA levels were normalized to GAPDH mRNA levels. Data from long-term experiments were pooled from three to five experiments ranging in length from 20 to 35 days in duration.

\section{Western blot analysis}

Proteins from engineered tissues were isolated by suspending each tissue in $250 \mu 1$ lysis buffer (23) containing $25 \mathrm{mM}$ Tris, $\mathrm{pH} 7.4,0.4 \mathrm{M} \mathrm{NaCl}, 0.5 \%$ SDS with protease inhibitors $(10 \mu \mathrm{g} / \mathrm{ml}$ aprotinin, $10 \mu \mathrm{g} / \mathrm{ml}$ leupeptin, $5 \mu \mathrm{g} / \mathrm{ml}$ pepstatin, and $0.5 \mathrm{M} \mathrm{PMSF}$ ) and freezing. After thawing, tissues were crushed manually with a microfuge tube tissue pulverizer, vortexed, and centrifuged. Supernatants were analyzed for DNA by using Hoechst 33258 dye and a fluorometer (Hoefer DyNA Quant 200, Pharmacia Biotech, Uppsala, Sweden) (27). Protein samples representing equal amounts of DNA from each sample were mixed with Laemmli sample buffer (1:1, Bio-Rad, Hercules, CA), and proteins were separated by SDS-PAGE on 10$20 \%$ Tris- $\mathrm{HCl}$ reducing gels (Bio-Rad). Proteins were then transferred to polyvinylidene difluoride (PVDF) membranes (Bio-Rad). Membranes were blocked with 5\% dried milk in TBS$\mathrm{T}(0.1 \%$ Tween-20 in TBS) for $1 \mathrm{~h}$ and probed with mouse anti-OPN antibody (MPIIIB10; Developmental Studies Hybridoma Bank, Iowa City, IA) diluted 1:50 with TBS-T for $1 \mathrm{~h}$ at $25^{\circ} \mathrm{C}$. Membranes were then washed and incubated with 1:1000 dilution of horseradish peroxidase-conjugated anti-mouse IgG (Bio-Rad) for $1 \mathrm{~h}$. Detection was by chemiluminescence with an enhanced chemiluminescence kit (Amersham). Bands were quantified densitometrically by scanning films into Scion Image (NIH Image) and analyzed $(n=3)$. 


\section{Histological analysis}

For histological analysis, samples were fixed in Z-Fix (Anatech, Battle Creek, MI), paraffin embedded, sectioned, and stained with Gill 3 hematoxylin (Sigma) and eosin (Sigma). For immunostaining, sections were deparaffinized and washed for $5 \mathrm{~min}$ in $3 \% \mathrm{H}_{2} \mathrm{O}_{2}$ (Sigma) to quench endogenous peroxidases. After incubating for $10 \mathrm{~min}$ with terminator blocking solution (Biocare Medical, Walnut Creek, CA) to prevent nonspecific antibody-antigen interactions, sections were allowed to incubate with antibodies to OPN (MPIIIB10), diluted 1:50, for $1 \mathrm{~h}$ at $37^{\circ} \mathrm{C}$. Biotinylated universal link (Biocare Medical) secondary antibody was used for $30 \mathrm{~min}$ followed by a 15-min incubation with streptavidin-HRP (Biocare Medical). The HRP reaction was completed with 3,3-diaminobenzidine (Zymed, South San Francisco, CA) for 10 min. Tissue sections were visualized using a Nikon Ellipse E800 microscope.

\section{Biochemical assays}

Alkaline phosphatase activity was measured from cell lysates using $p$-nitrophenyl phosphate substrate as described previously (28). Enzyme activity was normalized to total DNA in the tissue, determined by the Hoechst 33258 fluorescent dye binding assay $(n=3)$.

Calcification of tissues was assessed by a modification of the method described by Wada et al. (4). Tissues were rinsed thoroughly in PBS and exposed to lysis buffer as described previously. Supernatants were analyzed for DNA as described and calcium by the $o$-cresolphthalein complexone method (Calcium Kit, Sigma). The remaining solids were minced and decalcified with $0.6 \mathrm{~N} \mathrm{HCl}$ for $24 \mathrm{~h}$. The $\mathrm{HCl}$ supernatant was assayed for calcium as well. Calcium content from the lysate (cell-associated, soluble calcium) and $\mathrm{HCl}$ (matrix-associated, deposited calcium) supernatants was added together, and values were normalized to total DNA content in the tissues $(n=3)$.

\section{Statistical analysis}

Data were expressed as the means \pm SD. Statistical comparisons were performed using unpaired Student's $t$ test (InStat, GraphPad Software). A value of $P<0.05$ was considered to be statistically significant unless otherwise noted.

\section{RESULTS}

To confirm that rat aortic SMCs express OPN, we isolated total RNA from cells following culture on standard tissue culture flasks for varying time periods. As expected, OPN mRNA levels increased over time in cultured cells (Fig. 2). However, 2-D cell culture is a poor representation of the natural tissue environment of SMCs, which is 3-D, is mechanically dynamic, and involves the interaction of multiple cell types. To determine whether up-regulation of OPN resulted solely from the 2-D culture conditions, smooth muscle tissues were engineered to mimic the 3-D aspect of the normal environment by seeding and culturing SMCs in type I collagen sponges (Fig. 3a and $\underline{3 c}$ ). Cells within the tissues adhered, proliferated, and produced their own ECM to form 3-D tissues (Fig. 3b and 3d). Immunohistochemical analysis revealed significant OPN deposition around cells within engineered tissues (Fig. $3 \mathrm{e}$ and $\underline{3 \mathrm{f}}$ ), and OPN expression increased with time in a similar manner (Fig. $3 g$ ) as observed in 2-D culture. 
The role of mechanical stimulation on OPN expression by SMCs in the engineered tissues was investigated by exposing tissues to cyclic mechanical strain $(7 \%, 1 \mathrm{~Hz})$ in a custom-made bioreactor. To ensure that the strain being applied to the clamped substrate was uniform along its entire length, the mechanical strain device was first characterized. A collagen sponge was positioned within the device, and the strain was quantified within a grid pattern of nine regions superimposed on the sponge (three lines parallel to strain direction, three lines perpendicular to strain direction). Measurements of the strain at each point parallel to the strain direction revealed a consistent amount of strain along the length of the membrane (Fig. 4). However, a gradient of strain was apparent in the perpendicular axis, with maximal strain occurring in the middle of the sponge, along the outer regions. Previous studies have demonstrated that the collagen sponges used in these experiments exhibit little permanent deformation with this pattern of constant repeated strain application (29).

OPN protein within engineered tissues was first analyzed after 15 days in culture, using Western analysis of tissue lysates. Quantification of triplicate samples over multiple experiments revealed a 2.2-fold decrease in OPN protein deposited in strained as compared with nonstrained tissues (Fig. 5). To confirm the mechanical responsiveness of OPN expression in SMCs, similar studies measuring OPN levels were performed with mRNA isolated from 2-D cultures of cells adherent to an elastic membrane and cyclically strained. The short-term (2-day) response of cells in this system revealed a similar expression pattern for OPN (data not shown) to that observed in the 3D system. However, the effect of strain on long-term cell phenotype in this system could not be ascertained, because cell sheets began to detach from membranes beyond $1 \mathrm{wk}$ of culture.

Experiments were next performed to determine whether strain regulated a larger-scale phenotypic change of SMCs to a bonelike pattern of gene expression in the engineered tissues. OPN mRNA expression in control tissues (maintained in bioreactor with no strain application) increased over time (Fig. 6a), as noted in standard culture conditions (Fig. 3g). However, tissues exposed to chronic strain maintained low and fairly constant OPN levels, leading to unstrained tissues expressing between 2.7 and 4.1 times the OPN mRNA amounts of strained tissues after 5 wk and 5 months, respectively (Fig. 6a). A small, but reproducible increase in mRNA levels in strained vs. control tissues was found, however, at the earliest time point (2 days). A panel of genes typically recognized as markers for osteoblast differentiation was also studied. mRNA levels of CBFA-1, a transcription factor controlling OPN expression and normally associated with osteoblast differentiation, were quantified in strained vs. nonstrained engineered tissues. CBFA-1 mRNA levels followed a similar temporal profile as OPN, as expected for a transcription factor and the gene it regulates. Strained tissues maintained fairly constant mRNA levels over time, but unstrained tissues exhibited higher message levels for the 5-wk duration of the experiment (Fig. 6b). We then investigated the expression of MGP, another protein implicated in the calcification process. Expression of MGP followed a similar pattern to that of OPN, as levels were up-regulated over time in culture in control tissues, and this effect was again largely eliminated with application of cyclic strain (Fig. 6c). To determine the reproducibility of these results, we pooled the effect of cyclic strain on long-term levels of OPN, MGP, and CBFA1 mRNA in multiple experiments, and levels for all three genes were found to be significantly lower than control/unstrained tissues. Message levels for OPN, MGP, and CBFA-1 in strained tissues decreased by 2.1, 1.7, and 2.0 times, respectively, as compared with control tissues (Fig. $\underline{6 \mathrm{~d}})$. 
Finally, engineered tissues were analyzed to determine whether the noted changes in gene expression were paralleled by changes in cell phenotype leading to mineralization. The activity of alkaline phosphatase, an enzyme involved in mineral formation and an established osteoblast differentiation marker, was determined in strained vs. unstrained engineered tissues. There were no differences between strained and control tissues at the initial time points analyzed, but at 5 wk, the alkaline phosphatase activity in control tissues was more than 3.5 times greater than in tissues exposed to cyclic strain (Fig. 7a). Not surprisingly, the changes in SMC phenotype resulting from long-term cyclic strain led to significant variations in the total calcium deposited within tissues. Exposure to strain for $5 \mathrm{wk}$ caused a significant decrease in the amount of calcium deposited in strained tissues, as compared with control tissues (Fig. 7b) .

\section{DISCUSSION}

Vascular calcification is a common health problem and is thought to be an actively regulated process similar to osteogenesis. Mechanical stresses and strains are clearly significant extracellular stimuli that regulate the phenotype of vascular SMCs and play an important role in the development of hypertension and atherosclerosis (30). Although mechanical strain has been associated with these disease processes, there is little previous evidence implicating strain in modulating the calcification process regulated by SMCs. As demonstrated in these studies, cyclic mechanical strain inhibits a phenotypic switch of SMCs to a pattern of gene expression more typical for bone, and thus relevant to calcification. A 3-D smooth muscle tissue model system composed of SMCs grown within type I collagen sponges revealed that the expression of a variety of markers implicated with various stages of bone differentiation and calcification (OPN, CBFA-1, MGP, alkaline phosphatase) was found to be up-regulated over time in static culture. In addition, not only were these markers responsive to mechanical stimuli, but chronic stimulation was found to down-regulate the expression of these bone-associated genes and play a protective role in calcification. These data suggest that cyclic mechanical strain is an important signal inhibiting the expression of genes associated with calcification.

SMCs grown in static culture were found to up-regulate the expression of markers associated with bone differentiation over time. Cells cultured statically in two-dimensions, as well as within a 3-D engineered tissue, exhibited an increase in early markers of bone differentiation (e.g., CBFA-1, a transcription factor normally associated with the differentiation of osteoblasts), as well as markers associated with bone matrix maturation (e.g., alkaline phosphatase, OPN, and MGP). The observation that these genes are expressed by vascular cells is not a new one, as recent evidence has implicated a similar phenotypic transition associated with calcification within SMC cultures, noted by increases in CBFA-1, OPN, osteocalcin, and alkaline phosphatase and decreases in smooth muscle lineage markers SM22 and $\alpha$-smooth muscle actin $(2,13)$. Similarly, a calcifying cell line has been isolated from aortas expressing OPN, alkaline phosphatase, and bone morphogenetic protein-2, further providing proof for the existence of cells demonstrating a bonelike phenotype within the vasculature (31).

The studies outlined here are, however, the first to demonstrate the modulation of expression of these bone-associated proteins in smooth muscle by long-term application of strain. In agreement with the finding that cyclic mechanical strain suppresses bone-associated gene expression, strain was also found to play a protective role in calcification in this system. This effect was found even though cells were cultured under normal, noncalcification-inducing conditions (e.g., no 
addition of calcification agents such as $\beta$-glycerolphosphate). Several previous studies clearly document that application of strain can have significant effects on SMC phenotype (e.g., cell alignment, protease expression) in engineered tissues $(32,33)$ but have not examined the expression of bone-associated genes. Our findings with OPN are supported by a previous study demonstrating that short-term pressure modulates expression of OPN in cultured human aortic SMCs (34). Similarly, following the removal of mechanical stimulus, an up-regulation of OPN and MGP was demonstrated over time when aortic rings were excised from rats and grown in static culture (11). The relevance of a mechanically controlled SMC phenotype switch, as demonstrated in this study, is also supported by previous findings that demonstrate an upregulation of bone-associated genes in the neointima of injured or atherosclerotic arteries $(9,15)$ or in other situations that result in an altered mechanical environment of SMCs (3).

The effects of mechanical signals on SMC and smooth muscle tissue function are likely complex and dependent on the specific mechanical signal received by the cells. Previous studies clearly suggest that cyclic strain, in contrast to static strain, plays a significant role in the phenotypic modulation of SMCs from the synthetic to the contractile state (35) and in protein kinase A and $\mathrm{C}$ signaling (36). In support of these findings, we have previously documented that focal adhesion and cytoskeletal changes induced within rat SMCs by strain application are distinct for static vs. cyclic strain $(37,38)$. For example, recruitment of vinculin and paxillin to SMC focal adhesions occurs only following a minimum number of strain cycles, and not with a static stretch (38). The importance of an appropriate strain regime has also been demonstrated with cultured chondrocytes and bone cells (39-41). These findings may be related to a cell's ability to rearrange their adhesions to find a lower stress state when subjected to a static strain, thus relieving the imposed load. The exact strain sustained by cells is likely affected by several factors, including the microstructure of the matrix to which they are adherent and matrix fiber orientation. Previous studies with a simple 2-D strain system have documented the transferal of strain to SMCs adherent to elastic membranes (37). Extending these studies to include the complexity of a 3-D environment and the effects of cyclic strain remain a challenge. Also note that SMCs in vivo typically experience a complex strain environment that is not fully replicated by the relatively simple strain pattern used in the current study.

In contrast to the chronic effects of cyclic strain, a small but reproducible up-regulation of both OPN and CBFA-1 gene expression was noted following 2 days of strain. The parallel expression profiles of OPN and CBFA-1 in both short- and long-term responses is not surprising, because CBFA-1 has been shown to regulate the expression of $\operatorname{OPN}(26,42)$. We speculate that the shortterm up-regulation of these genes is due to an injury response by the cells, because they may interpret the onset of strain as an injury due to their maintenance in static culture before the start of these experiments. It has been previously reported that OPN delivers a receptor-mediated prosurvival, antiapoptotic signal to cells following injury (43) and may provide pro- and antiinflammatory effects in vivo.

The use of a tissue-engineered, 3-D model holds great promise as a tool with which to study vascular biology and disease. SMCs maintained in more typical 2-D culture detached from the culture surface with long-term application of continuous cyclic strain, precluding the use of that system in the experiments performed in the current study. Furthermore, the tissue model used in this study has been previously characterized to exhibit a similar ECM composition (e.g., collagen and elastin content) and SMC density as native smooth muscle tissue $(27,44)$. The application of 
cyclic strain was found to alter matrix synthesis and lead to enhanced alignment of matrix and cells in the tissues (21). The cell response to cyclic strain observed in the current study is likely mediated by the type and organization of this cell-assembled matrix. Tissue-engineered cardiovascular model systems have also been used to study the pharmacological effects of various drugs (45), ECM production and turnover within blood vessels $(32,46)$, and the effect of matrix structure on cell alignment (33) and have shown utility in vivo as potential replacement tissues $(47,48)$. One limitation to the use of these systems for in vitro studies is the lack of vascularization and resulting loss of viability of cells in the interior of these tissues. This was observed in the present study; viable SMCs were present only in the exterior regions of the engineered tissues. However, various bioreactor systems have been developed to alleviate the transport limitations inherent to static in vitro culture systems and allow for thicker tissues to be grown in vitro $(49,50)$. In any case, engineered tissue systems allow the replication of particular aspects of native tissue, such as their 3-D architecture and the presence of mechanical signals. The versatility of this model system also potentially allows for other complexities of the vascular environment, such as the presence of different cell types (e.g., fibroblasts, endothelial cells, macrophages) or the involvement of circulating cytokines, to be examined in a controlled manner.

Altogether, the results of this study lead to a model outlining the effects of mechanical strain on SMC phenotype that suggests SMCs undergo a phenotypic conversion to a more osteoblast-like pattern of gene expression without an appropriate mechanical signal (e.g., exposure to cyclic mechanical strain) (Fig. 8). However, exposure to strain maintains the SMC phenotype, as supported by past findings of enhanced cell and matrix organization, increased tissue mechanical properties, and increased myofilament bundles in these engineered smooth muscle tissues (21). In contrast to bone, in which mechanical stimuli have been shown to enhance mineral deposition (51), mechanical strain within this smooth muscle model system had an inhibitory effect on mineralization. Normally within the cardiovasculature, smooth muscle tissues are constantly exposed to mechanical strain due to vessel wall distension. It is hypothesized that a disruption of the normal vessel architecture and thus normal mechanical environment, which occurs with disease or balloon angioplasty, could be one mechanism responsible for the calcification seen with these conditions. This model may generally aid in interpreting and preventing the calcification of vascular tissues commonly observed in various pathologic and therapeutic situations in which the mechanical environment of the tissue is altered. Furthermore, these data provide support to the plasticity of the smooth muscle phenotype and its regulation by environmental factors such as mechanical strain. Finally, this report indicates the utility of engineered tissues for basic biology studies, because the desired features of normal tissues (e.g., 3-D architecture) can be controllably built into a highly defined model system.

\section{ACKNOWLEDGMENTS}

This study was supported by an American Heart Association Fellowship to J.N. and by the National Institutes of Health (R01 DE13349).

\section{REFERENCES}

1. Giachelli, C. M. (2001) Ectopic calcification: new concepts in cellular regulation. $Z$. Kardiol. 90, Suppl 3, 31-37 
2. Jono, S., McKee, M. D., Murry, C. E., Shioi, A., Nishizawa, Y., Mori, K., Morii, H., Giachelli, C. M. (2000) Phosphate regulation of vascular smooth muscle cell calcification. Circ. Res. 87, E10-E17

3. Demer, L. L. (1995) A skeleton in the atherosclerosis closet. Circulation 92, 2029-2032

4. Wada, T., McKee, M. D., Steitz, S., Giachelli, C. M. (1999) Calcification of vascular smooth muscle cell cultures: inhibition by osteopontin. Circ. Res. 84, 166-178

5. Shioi, A., Nishizawa, Y., Jono, S., Koyama, H., Hosoi, M., Morii, H. (1995) Betaglycerophosphate accelerates calcification in cultured bovine vascular smooth muscle cells. Arterioscler. Thromb. Vasc. Biol. 15, 2003-2009

6. Proudfoot, D., Skepper, J. N., Shanahan, C. M., Weissberg, P. L. (1998) Calcification of human vascular cells in vitro is correlated with high levels of matrix Gla protein and low levels of osteopontin expression. Arterioscler. Thromb. Vasc. Biol. 18, 379-388

7. Watson, K. E., Bostrom, K., Ravindranath, R., Lam, T., Norton, B., Demer, L. L. (1994) TGF-beta 1 and 25-hydroxycholesterol stimulate osteoblast-like vascular cells to calcify. J. Clin. Invest. 93, 2106-2113

8. Stein, G. S., Lian, J. B., Owen, T. A. (1990) Relationship of cell growth to the regulation of tissue-specific gene expression during osteoblast differentiation. FASEB J. 4, 3111-3123

9. Giachelli, C. M., Bae, N., Almeida, M., Denhardt, D. T., Alpers, C. E., Schwartz, S. M. (1993) Osteopontin is elevated during neointima formation in rat arteries and is a novel component of human atherosclerotic plaques. J. Clin. Invest. 92, 1686-1696

10. Shanahan, C. M., Cary, N. R., Metcalfe, J. C., Weissberg, P. L. (1994) High expression of genes for calcification-regulating proteins in human atherosclerotic plaques. J. Clin. Invest. 93, 2393-2402

11. Hao, H., Hirota, S., Tsukamoto, Y., Imakita, M., Ishibashi-Ueda, H., Yutani, C. (1995) Alterations of bone matrix protein mRNA expression in rat aorta in vitro. Arterioscler. Thromb. Vasc. Biol. 15, 1474-1480

12. Gadeau, A. P., Campan, M., Millet, D., Candresse, T., Desgranges, C. (1993) Osteopontin overexpression is associated with arterial smooth muscle cell proliferation in vitro. Arterioscler. Thromb. 13, 120-125

13. Steitz, S. A., Speer, M. Y., Curinga, G., Yang, H. Y., Haynes, P., Aebersold, R., Schinke, T., Karsenty, G., Giachelli, C. M. (2001) Smooth muscle cell phenotypic transition associated with calcification: upregulation of $\mathrm{Cbfa} 1$ and downregulation of smooth muscle lineage markers. Circ. Res. 89, 1147-1154

14. Bostrom, K., Watson, K. E., Horn, S., Wortham, C., Herman, I. M., Demer, L. L. (1993) Bone morphogenetic protein expression in human atherosclerotic lesions. J. Clin. Invest. 91, 1800-1809 
15. Yamamoto, M., Aoyagi, M., Azuma, H., Yamamoto, K. (1997) Changes in osteopontin mRNA expression during phenotypic transition of rabbit arterial smooth muscle cells. Histochem. Cell Biol. 107, 279-287

16. Lehoux, S., Tedgui, A. (1998) Signal transduction of mechanical stresses in the vascular wall. Hypertension 32, 338-345

17. Ross, R. (1993) The pathogenesis of atherosclerosis: a perspective for the 1990s. Nature 362, 801-809

18. Wozniak, M., Fausto, A., Carron, C. P., Meyer, D. M., Hruska, K. A. (2000) Mechanically strained cells of the osteoblast lineage organize their extracellular matrix through unique sites of alphavbeta3-integrin expression. J. Bone Miner. Res. 15, 1731-1745

19. Kaspar, D., Seidl, W., Neidlinger-Wilke, C., Ignatius, A., Claes, L. (2000) Dynamic cell stretching increases human osteoblast proliferation and CICP synthesis but decreases osteocalcin synthesis and alkaline phosphatase activity. J. Biomech. 33, 45-51

20. Meyer, U., Meyer, T., Vosshans, J., Joos, U. (1999) Decreased expression of osteocalcin and osteonectin in relation to high strains and decreased mineralization in mandibular distraction osteogenesis. J. Craniomaxillofac. Surg. 27, 222-227

21. Kim, B. S., Nikolovski, J., Bonadio, J., Mooney, D. J. (1999) Cyclic mechanical strain regulates the development of engineered smooth muscle tissue. Nat. Biotechnol. 17, 979-983

22. Parhami, F., Tintut, Y., Patel, J. K., Mody, N., Hemmat, A., Demer, L. L. (2001) Regulation of vascular calcification in atherosclerosis. Z. Kardiol. 90, Suppl 3, 27-30

23. Caron, J. M., Jones, A. L., Kirschner, M. W. (1985) Autoregulation of tubulin synthesis in hepatocytes and fibroblasts. J. Cell Biol. 101, 1763-1772

24. Cunningham, J. J., Nikolovski, J., Linderman, J., Mooney, D.J. (2002) Quantification of fibronectin adsorption to silicone-rubber cell culture substrates. Biotechniques 32(4), 876-880

25. Crosby, A. H., Lyu, M. S., Lin, K., McBride, O. W., Kerr, J. M., Aplin, H. M., Fisher, L. W., Young, M. F., Kozak, C. A., Dixon, M. J. (1996) Mapping of the human and mouse bone sialoprotein and osteopontin loci. Mamm. Genome 7, 149-151

26. Ducy, P., Zhang, R., Geoffroy, V., Ridall, A. L., Karsenty, G. (1997) Osf2/Cbfa1: a transcriptional activator of osteoblast differentiation. Cell 89, 747-754

27. Kim, B. S., Putnam, A. J., Kulik, T. J., Mooney, D. J. (1998) Optimizing seeding and culture methods to engineer smooth muscle tissue on biodegradable polymer matrices. Biotechnol. Bioeng. 57, 46-54 
28. Manolagas, S. C., Burton, D. W., Deftos, L. J. (1981) 1,25-Dihydroxyvitamin D3 stimulates the alkaline phosphatase activity of osteoblast-like cells. J. Biol. Chem. 256, 71157117

29. Kim, B. S., Mooney, D. J. (2000) Scaffolds for engineering smooth muscle under cyclic mechanical strain conditions. J. Biomech. Eng. 122, 210-215

30. Li, C., Xu, Q. (2000) Mechanical stress-initiated signal transductions in vascular smooth muscle cells. Cell. Signal. 12, 435-445

31. Bostrom, K. I. (2000) Cell differentiation in vascular calcification. Z. Kardiol. 89, Suppl 2, 69-74

32. Seliktar, D., Black, R. A., Vito, R. P., Nerem, R. M. (2000) Dynamic mechanical conditioning of collagen-gel blood vessel constructs induces remodeling in vitro. Ann. Biomed. Eng. 28, 351-362

33. Girton, T. S., Oegema, T. R., Grassl, E. D., Isenberg, B. C., Tranquillo, R. T. (2000) Mechanisms of stiffening and strengthening in media-equivalents fabricated using glycation. $J$. Biomech. Eng. 122, 216-223

34. Iizuka, K., Murakami, T., Kawaguchi, H. (2001) Pure atmospheric pressure promotes an expression of osteopontin in human aortic smooth muscle cells. Biochem. Biophys. Res. Commun. 283, 493-498

35. Kanda, K., Matsuda, T. (1994) Mechanical stress-induced orientation and ultrastructural change of smooth muscle cells cultured in 3-D collagen lattices. Cell Transplant. 3, 481-492

36. Mills, I., Cohen, C. R., Kamal, K., Li, G., Shin, T., Du, W., Sumpio, B. E. (1997) Strain activation of bovine aortic smooth muscle cell proliferation and alignment: study of strain dependency and the role of protein kinase A and C signaling pathways. J. Cell. Physiol. 170, $228-234$

37. Putnam, A. J., Cunningham, J. J., Dennis, R. G., Linderman, J. J., Mooney, D. J. (1998) Microtubule assembly is regulated by externally applied strain in cultured smooth muscle cells. J. Cell Sci. 111, 3379-3387

38. Cunningham, J. J., Linderman, J. J., Mooney, D. J. (2002) Externally applied cyclic strain regulates localization of focal contact components in cultured smooth muscle cells. Ann. Biomed. Eng. 30, 927-935

39. Lee, D. A., Noguchi, T., Knight, M. M., O'Donnell, L., Bentley, G., Bader, D. L. (1998) Response of chondrocyte subpopulations cultured within unloaded and loaded agarose. $J$. Orthop. Res. 16, 726-733

40. Meyer, U., Meyer, T., Wiesmann, H. P., Kruse-Losler, B., Vollmer, D., Stratmann, U., Joos, U. (2001) Mechanical tension in distraction osteogenesis regulates chondrocytic differentiation. International Journal of Oral \& Maxillofacial Surger. 30, 522-530 
41. Meyer, U., Meyer, T., Schlegel, W., Scholz, H., Joos, U. (2001) Tissue differentiation and cytokine synthesis during strain-related bone formation in distraction osteogenesis. $B r . J$. Oral Maxillofac. Surg. 39, 22-29

42. Sato, M., Morii, E., Komori, T., Kawahata, H., Sugimoto, M., Terai, K., Shimizu, H., Yasui, T., Ogihara, H., Yasui, N., et al. (1998) Transcriptional regulation of osteopontin gene in vivo by PEBP2alphaA/CBFA1 and ETS1 in the skeletal tissues. Oncogene 17, 1517-1525

43. Denhardt, D. T., Noda, M., O'Regan, A. W., Pavlin, D., Berman, J. S. (2001) Osteopontin as a means to cope with environmental insults: regulation of inflammation, tissue remodeling, and cell survival. J. Clin. Invest. 107, 1055-1061

44. Kim, B. S., Nikolovski, J., Bonadio, J., Smiley, B., Mooney, D. J. (1999) Engineered smooth muscle tissues: regulating cell phenotype with the scaffold. Exp. Cell Res. 251, 318-328

45. L'Heureux, N., Stoclet, J. C., Auger, F. A., Lagaud, G. J., Germain, L., Andriantsitohaina, R. (2001) A human tissue-engineered vascular media: a new model for pharmacological studies of contractile responses. FASEB J. 15, 515-524

46. Stock, U. A., Wiederschain, D., Kilroy, S. M., Shum-Tim, D., Khalil, P. N., Vacanti, J. P., Mayer, J. E., Jr., Moses, M. A. (2001) Dynamics of extracellular matrix production and turnover in tissue engineered cardiovascular structures. J. Cell. Biochem. 81, 220-228

47. Hoerstrup, S. P., Sodian, R., Daebritz, S., Wang, J., Bacha, E. A., Martin, D. P., Moran, A. M., Guleserian, K. J., Sperling, J. S., Kaushal, S., et al. (2000) Functional living trileaflet heart valves grown in vitro. Circulation 102, III44-III49

48. Niklason, L. E., Gao, J., Abbott, W. M., Hirschi, K. K., Houser, S., Marini, R., Langer, R. (1999) Functional arteries grown in vitro. Science 284, 489-493

49. Pei, M., Solchaga, L. A., Seidel, J., Zeng, L., Vunjak-Novakovic, G., Caplan, A. I., Freed, L. E. (2002) Bioreactors mediate the effectiveness of tissue engineering scaffolds. FASEB $J$. published Aug 7, 2002, 10.1096/fj.02-0083fje

50. Sikavitsas, V. I., Bancroft, G. N., Mikos, A. G. (2002) Formation of 3-D cell/polymer constructs for bone tissue engineering in a spinner flask and a rotating wall vessel bioreactor. $J$. Biomed. Mater. Res. 62, 136-148

51. Wozniak, M., Fausto, A., Carron, C. P., Meyer, D. M., Hruska, K. A. (2000) Mechanically strained cells of the osteoblast lineage organize their extracellular matrix through unique sites of alphavbeta3-integrin expression. J. Bone Miner. Res. 15, 1731-1745

Received June 20, 2002; accepted November 25, 2002. 
Fig. 1

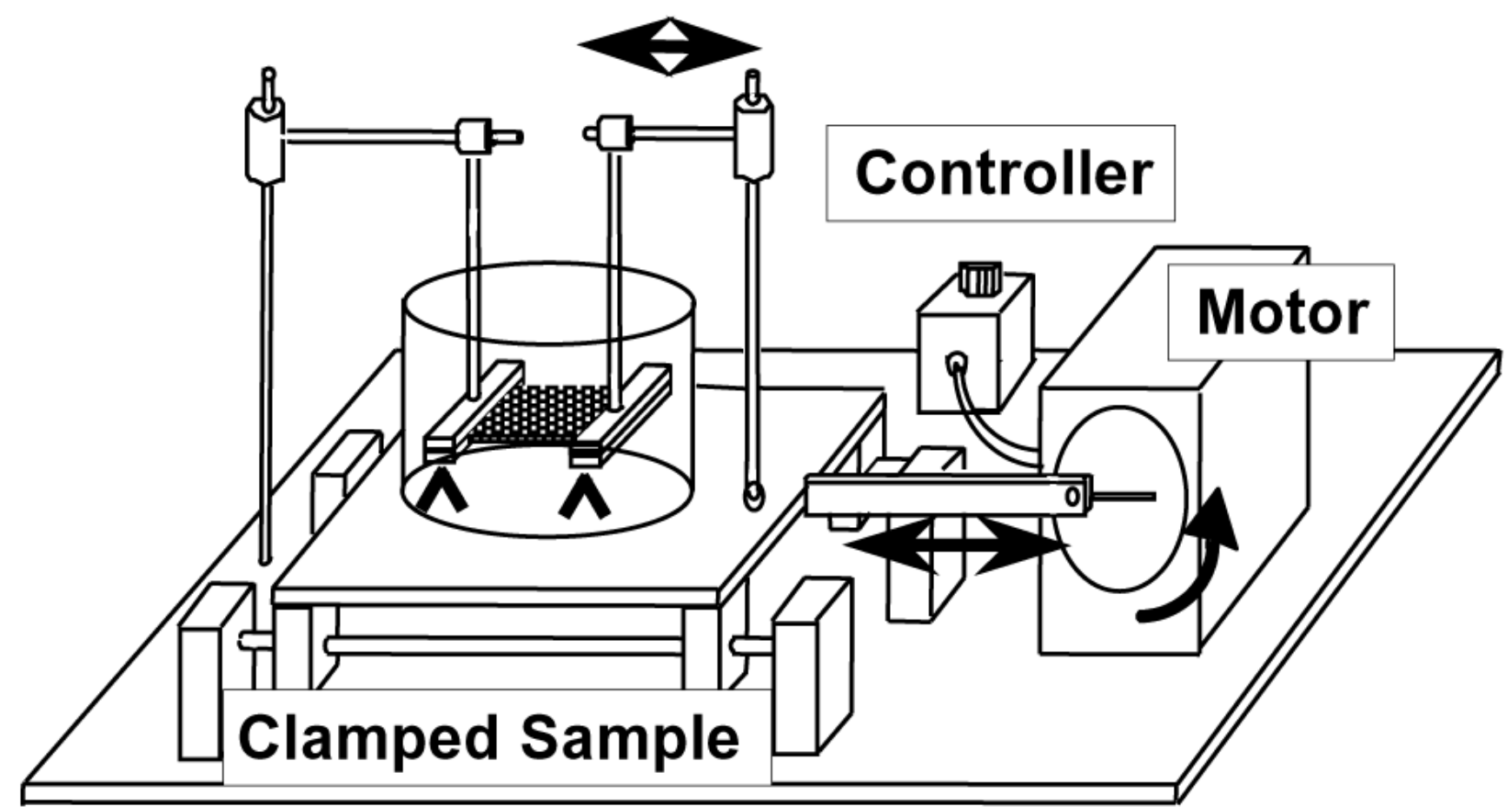

Figure 1. Tissue strain device. Engineered tissues were strained in a custom-made device. Samples were held between clamps (arrowheads), and one clamp was moved back and forth by a motorized eccentric disk, applying strain onto the sample (moving parts are indicated with arrows, along with direction of movement). Frequency was controlled using a dial-based controller, and amplitude was adjusted by varying the position of the arm attached to the eccentric disk. 
Fig. 2

A
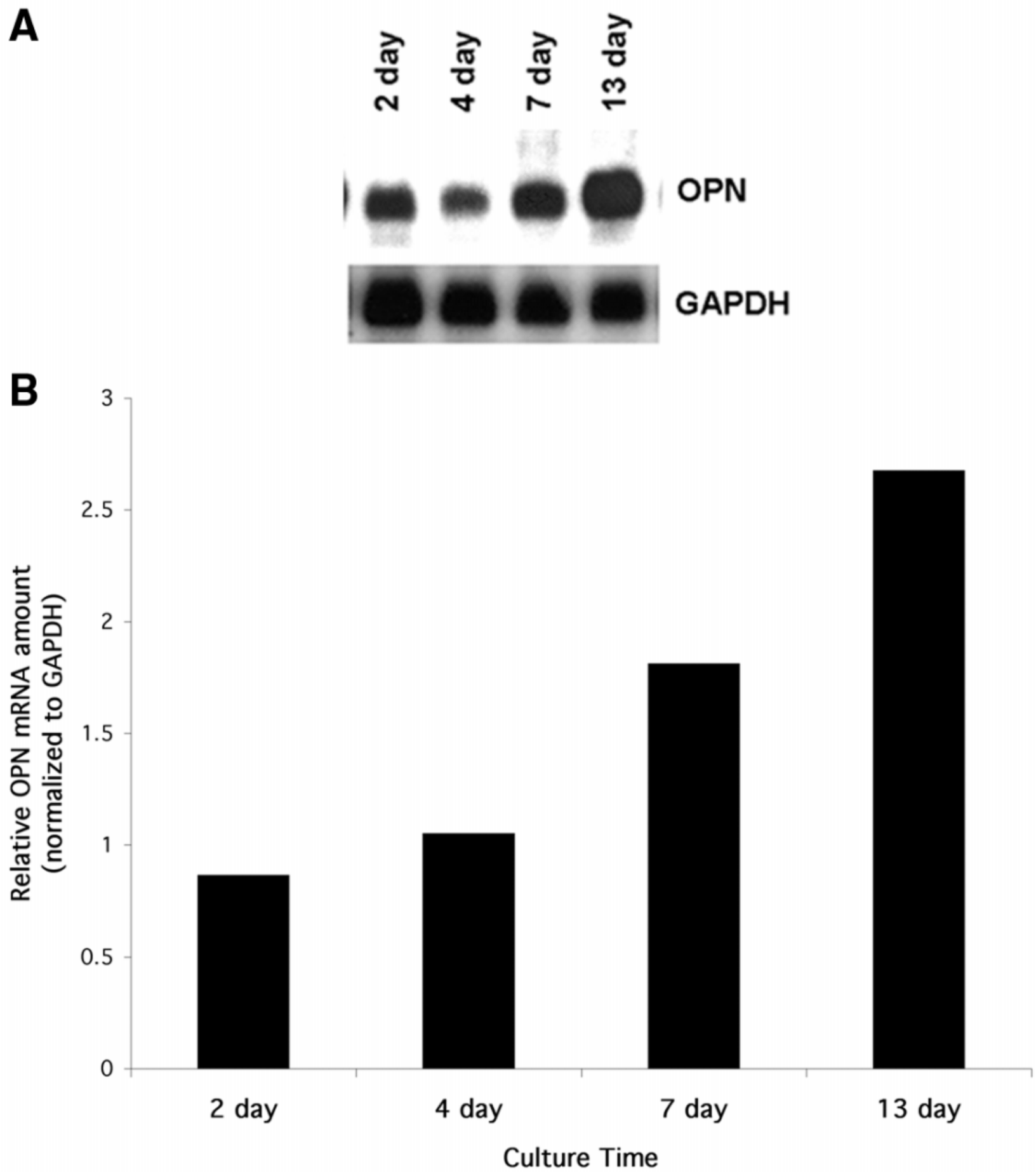

Figure 2. Smooth muscle cells increase expression of osteopontin over time in static culture. A) Northern blot showing osteopontin and the housekeeping gene glyceraldehyde phosphate dehydrogenase (GAPDH) mRNA bands from smooth muscle cells over time following plating onto polystyrene tissue culture dishes. B) Message levels were quantified and normalized to GAPDH message levels. 
Fig. 3
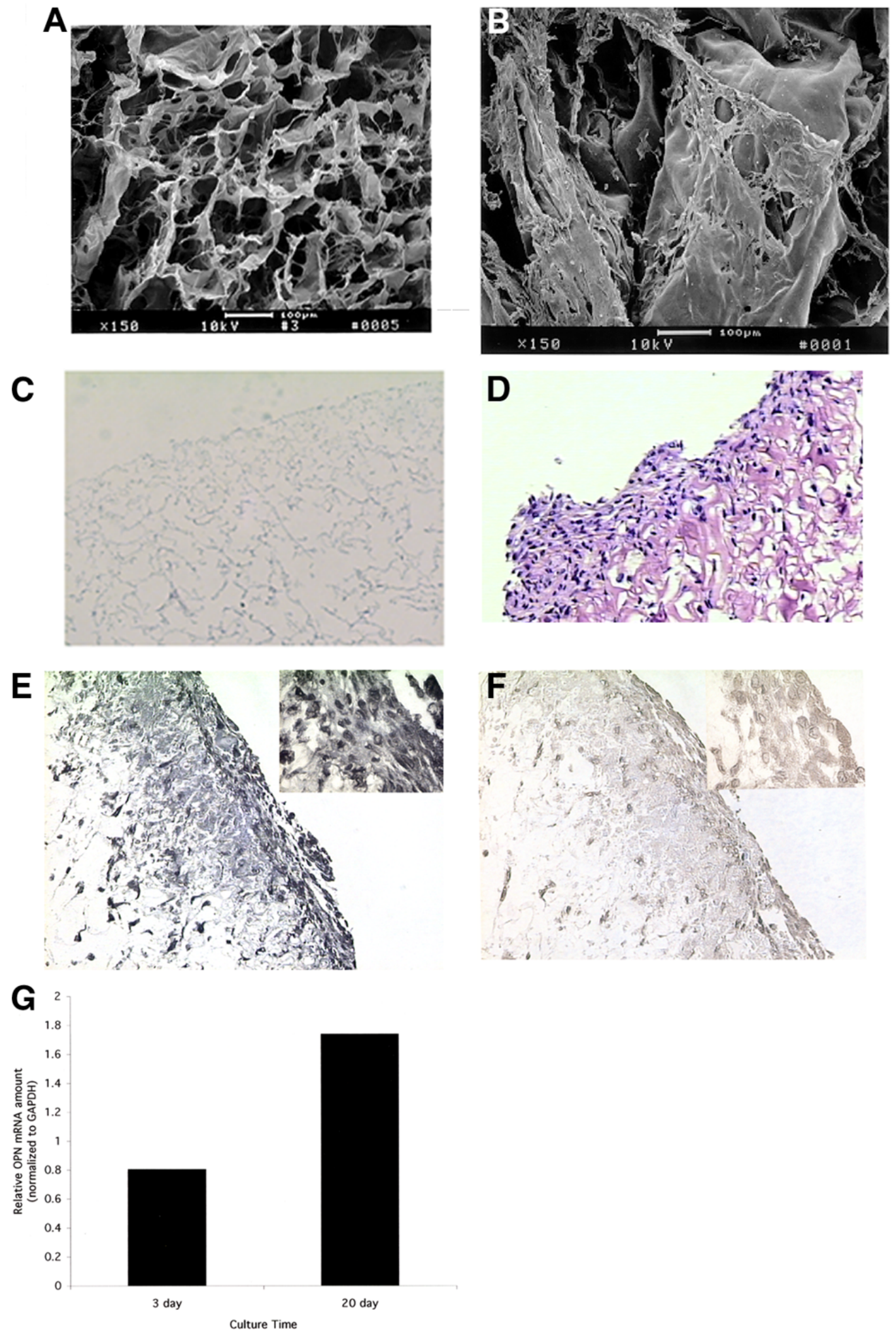

Figure 3. Osteopontin expression in engineered smooth muscle tissues. Scanning electron micrographs of collagen sponges (A) and sponges with adherent smooth muscle cells 3 days after cell seeding (B). Hematoxylin and eosin-stained sections of collagen sponges alone (C), and engineered smooth muscle tissues 23 days after seeding (D). Tissues grown for 5 wk under static culture expressed osteopontin as shown by immunohistochemical analysis (E), as compared with controls to which no primary antibody was added (F) (micrographs at 200× magnification, insets at 1000×). Osteopontin mRNA expression in tissues over time normalized to GAPDH levels (G). 
Fig. 4

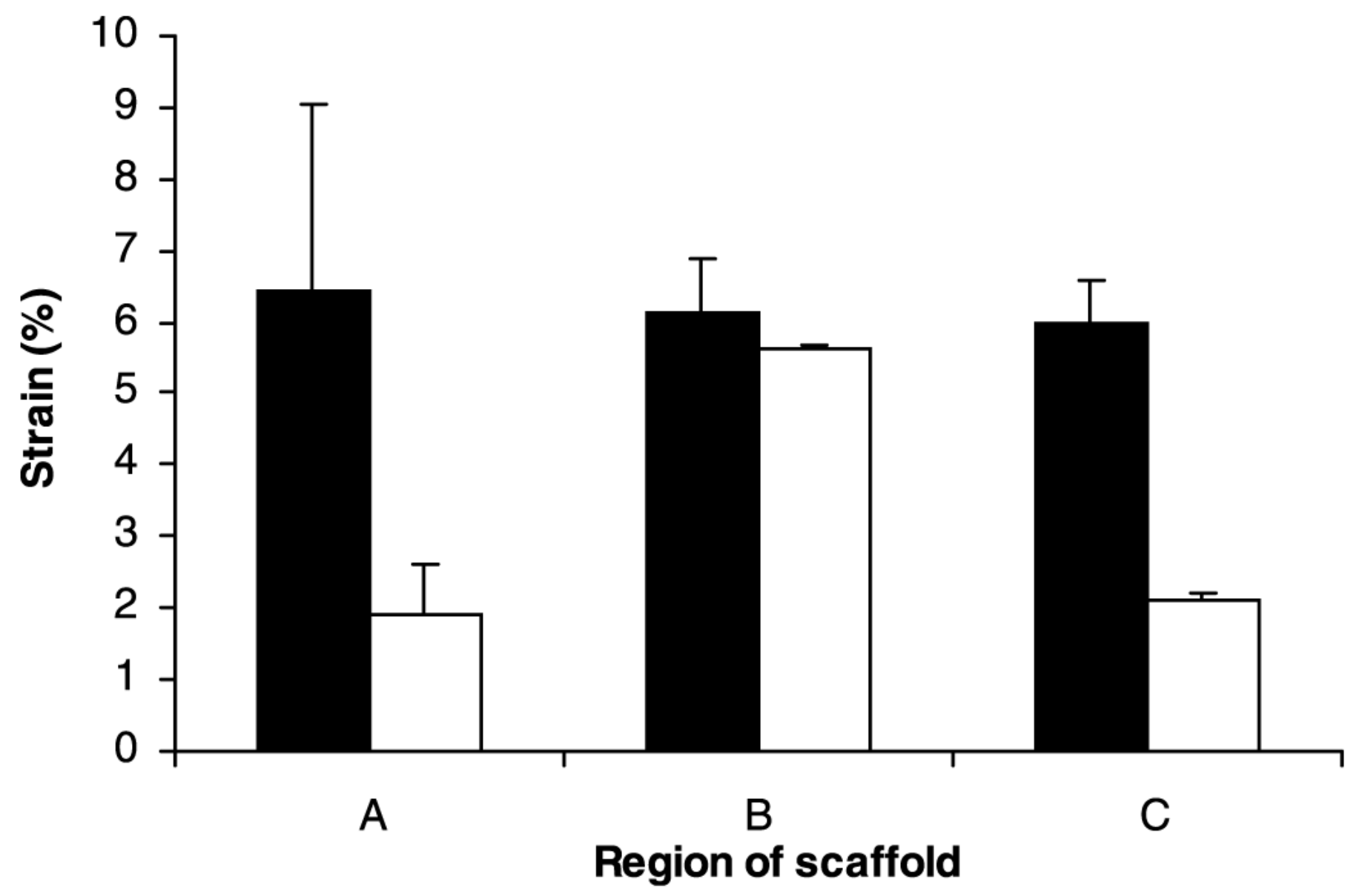

Figure 4. Strain profile in sponges. The strain profile in collagen sponges subjected to $7 \%$ strain by the custom device was evaluated in multiple regions, where region A was $1 \mathrm{~cm}$ from the stationary clamp, region B was in the middle, and region $\mathrm{C}$ was $3 \mathrm{~cm}$ from the stationary clamp. Substrate strain was evaluated at each point in both the parallel (black bars) and perpendicular (white bars) directions to the imposed strain direction. Values represent mean $(n=3)$ and standard deviation. 
Fig. 5

A

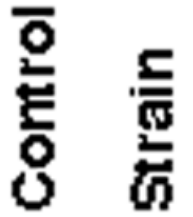

B

年

8000

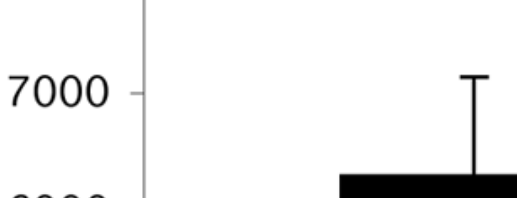

5000

4000

3000

2000

1000

0

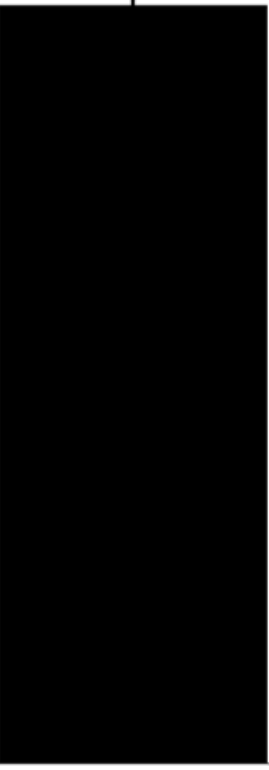

Control

Strain

Figure 5. Chronic cyclic strain down-regulates osteopontin in smooth muscle tissues. Representative Western blot (A) showing decreased amounts of osteopontin protein in tissues subjected to 15 days of cyclic strain, as compared with nonstrained tissues, and quantification of blots pooled from three experiments $(\mathbf{B}) ; * P<0.05$ as compared with nonstrained tissues. 
Fig. 6

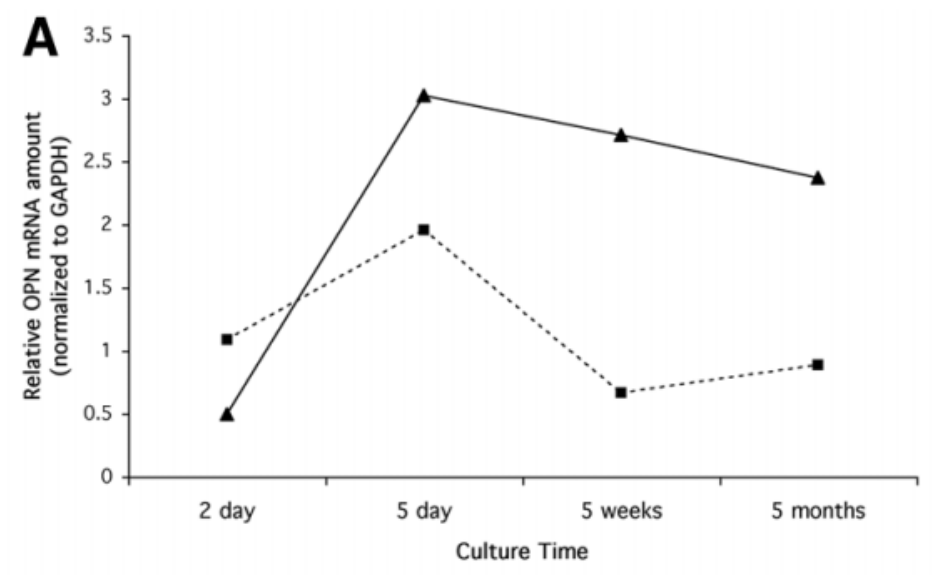

B
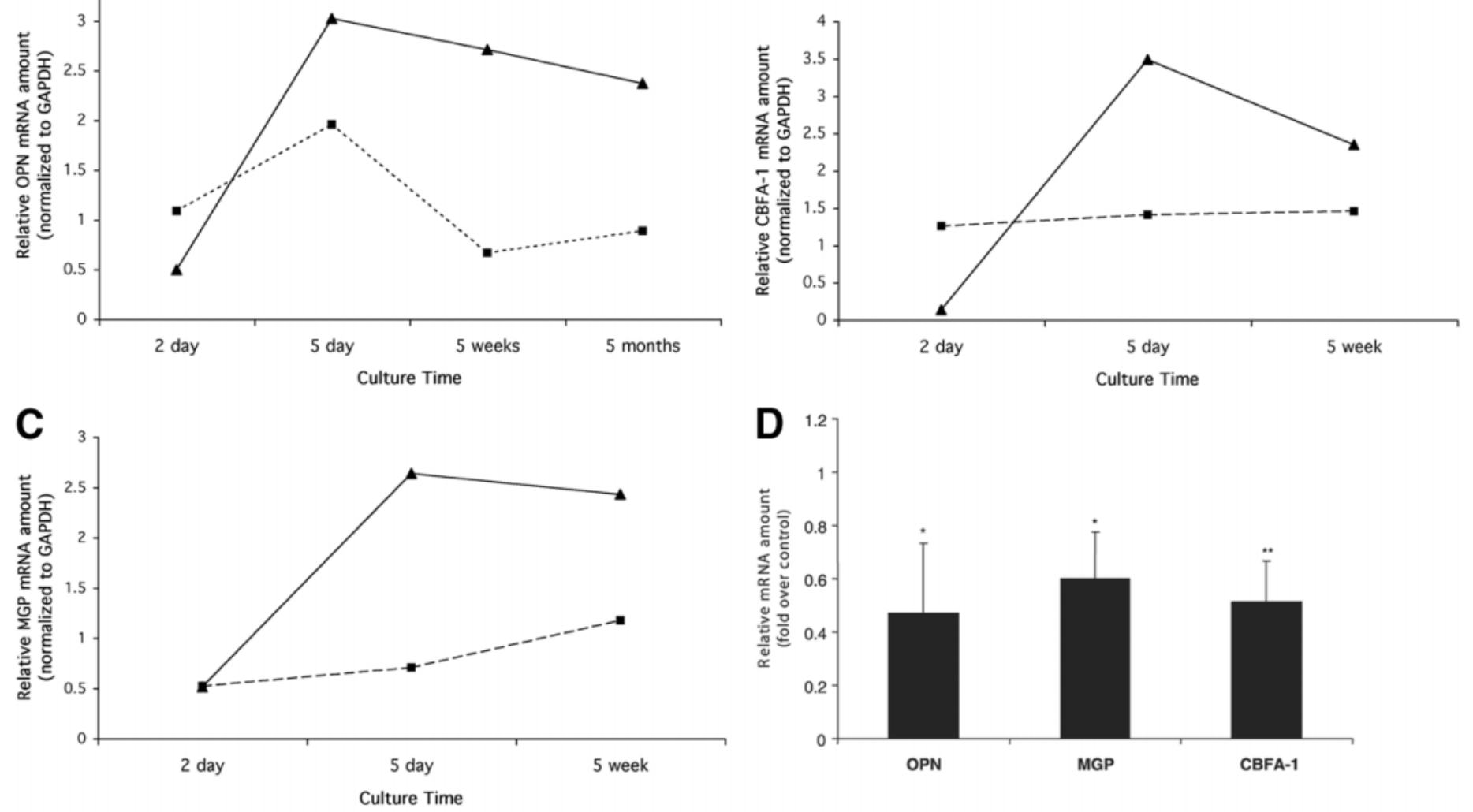

Figure 6. Chronic cyclic strain down-regulates bone-specific genes in smooth muscle tissues. Representative experiments showing osteopontin (OPN) (A), CBFA-1 (B), and matrix gla protein (MGP) (C) mRNA expression over time in smooth muscle tissues engineered with (dashed lines) or without (solid lines) exposure to cyclic strain. Northern blot analyses from multiple experiments run from 20 to 35 days were pooled, and values for mRNA levels are represented normalized to control, nonstrained tissue mRNA levels for each gene (D); ${ }^{*} P<0.05$, $* * P<0.1$ as compared with nonstrained tissues. 
Fig. 7

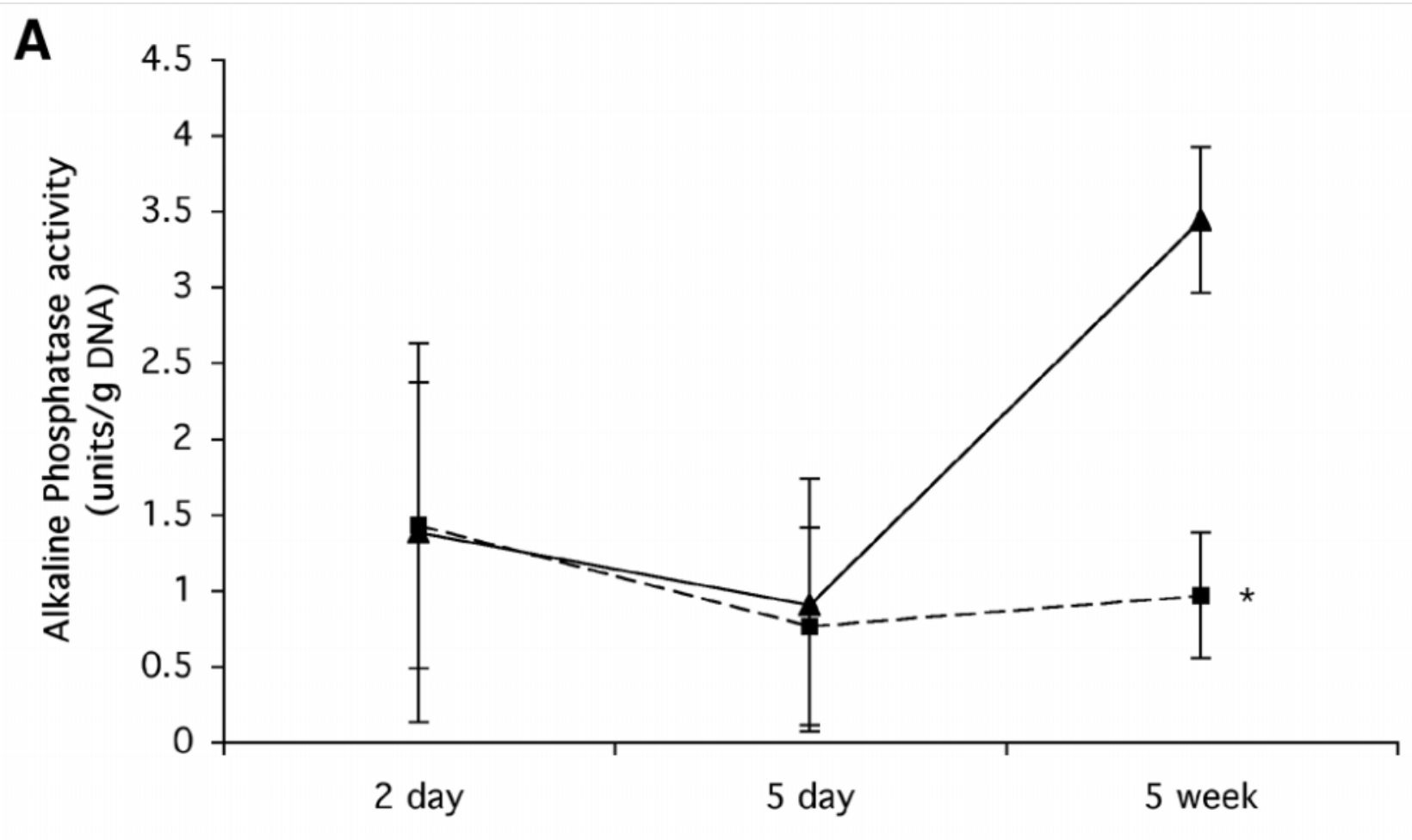

Culture Time

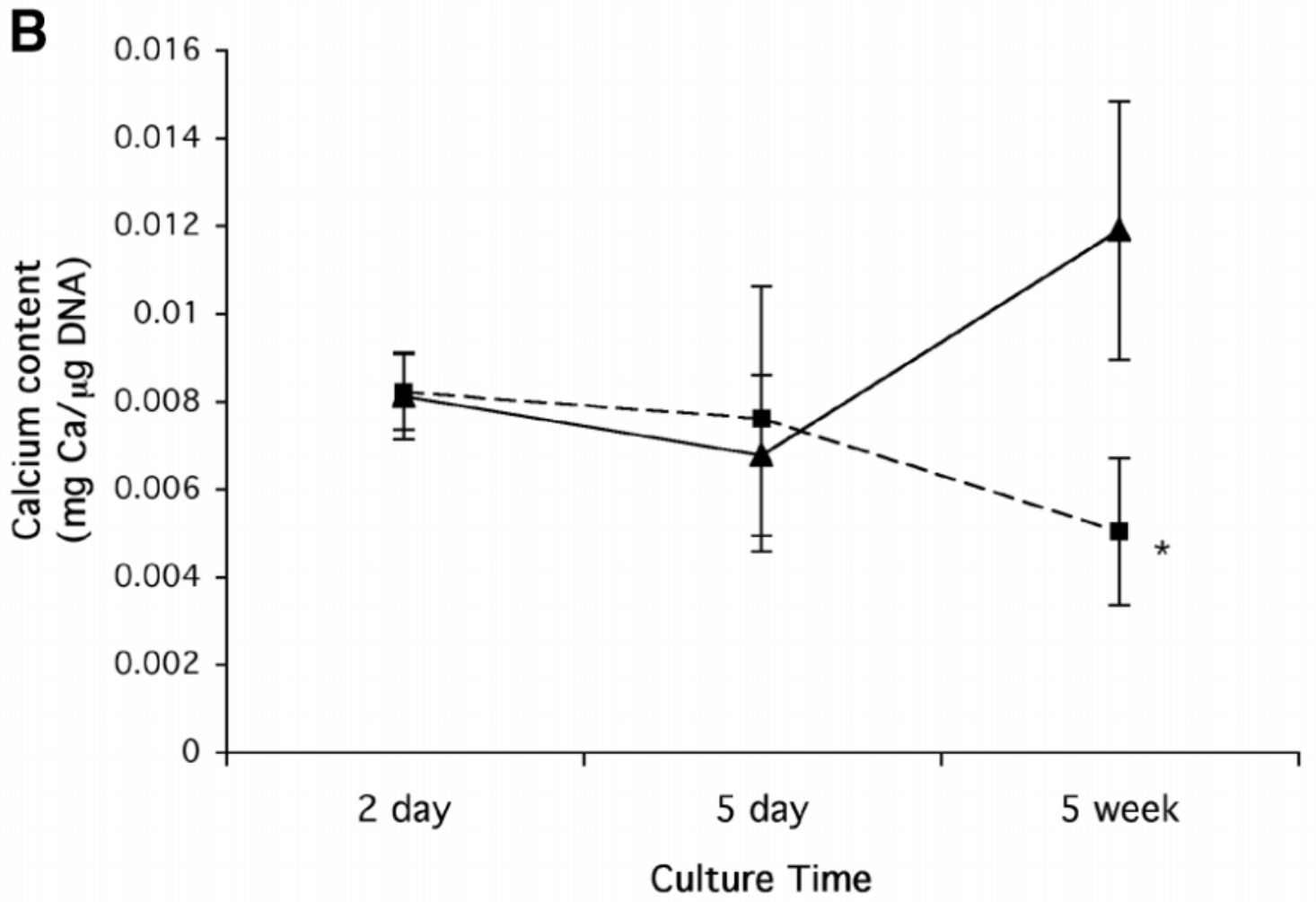

Figure 7. Long-term cyclic strain down-regulates mineralization markers in smooth muscle tissues. Quantification of alkaline phosphatase activity (A) and total calcium (B) in smooth muscle tissues engineered with (dashed lines) or without (solid lines) exposure to cyclic strain. Values represent mean $(n=3)$ and standard deviation. ${ }^{*} P<0.05$ as compared with nonstrained tissues. 
Fig. 8

\section{Synthetic Smooth \\ Muscle Cell}

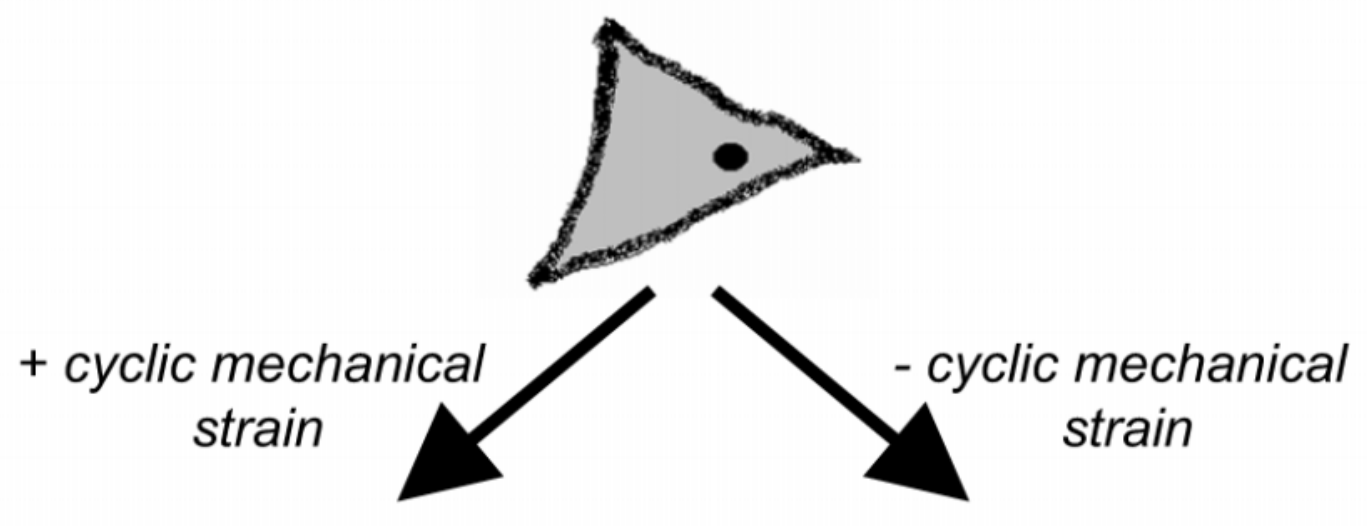

\section{Differentiated Smooth Muscle Cell

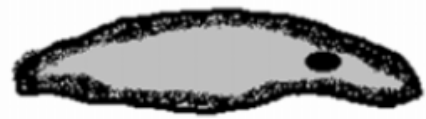

Increased myofilament bundles Increased alignment Increased mechanical properties

\section{Osteoblast-like Cell}

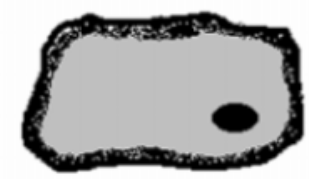

Increased OPN expression Increased CBFA-1 expression Increased MGP expression Increased alkaline phosphatase Increased calcification

Figure 8. Proposed model of the effect of long-term cyclic mechanical strain on the phenotype of smooth muscle cells. Cultured smooth muscle cells normally exist in the synthetic phenotype. Previous studies have demonstrated that exposing cells in engineered tissues to appropriate mechanical strain conditions converts the cells to a more differentiated phenotype, indicated by increased expression of myofilament bundles and increased cellular alignment. The current study demonstrates that tissues grown without the influence of strain increase their expression of genes indicative of an osteoblast phenotype and calcify to a greater extent. 